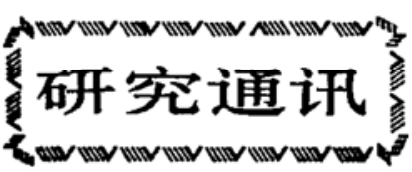

\title{
关于 Möbius 变换的半旋转分解 ${ }^{*}$
}

阶为 2 的二维保向 Möbius 变换称为是 半旋转 (记为 $H-T$ ). Maskit 在文献 [1] 中讨 论了二维保向 Möbius 变换关于 $H-T$ 的分 解. 本文继续讨论这种分解, 得到了双曲元 素关于 $H-T$ 的一种 “平行” 分解. 作为这 种几何分解的应用, 我们在 $H^{3}$ 中证明了 Beardon 关于 Riemann 面上短程线的一个 结果; 同时定义了 $n(n>2)$ 维的空间半旋转 (记为 $H-R$ ), 并讨论了 $n$ 维保向 Möbius 变 换关于 $H-R$ 的分解.

定义 I $H^{3}$ 中的两条短 程 线 $L_{1} 、 L_{2}$ 称为是平行的, 如果它们是同一平面中的两 条同心半圆弧, 或是两个平行平面在同一半 球面上所截得的两条半圆弧.

设 $f=\left(\begin{array}{ll}a & b \\ c & d\end{array}\right)$ 是 $n$ 维 Clifford 矩 阵, $f(x)=(a x+b)(c x+d)^{-1}, f$ 表示 $f$ 在 $R^{n+1}$ 中的 Poincaré 扩张.

定义 2 对于短程线 $L_{0}=\left\{\left(0, \cdots 0, x_{n+1}\right): x_{n+1}>0\right\}(n>2)$, 我们称 $\sigma_{0}=-I$ ( $I$ 为单位变换) 是关于 $L_{0}$ 的 $H-R$. 对任意 $H^{n+1}$ 中的短程线 $L$, 一定 存在 $n$ 维 Möbius 变换 $f$, 使得 $f(L)=L_{0}$, 则称 $\sigma=f^{-1} \sigma_{0} f$ 是关于 $L$ 的 $H-R$.

其它概念及记号均同文献 $[1,2] . n=2$.

定理 1 若 $f$ 是双曲的, 则对任意正. 交于 $A_{f}$ ( $f$ 的轴) 的短程线 $L_{1}$, 最多有一个 例外, 必存在另一条与 $A_{f}$ 正交, 且与 $L_{1}$ 平行 的短程线 $L_{2}$, 使得 $f=\sigma_{2} \sigma_{2}$, 其中 $\sigma_{i}(i=1$, 2) 是关于 $L_{i}$ 的 $H-T$.

定理 2 若 $L_{1} 、 L_{2}$ 是两条平行的短程
线, 则 $f=\sigma_{1} \sigma_{2}$ 是双曲的.

推论 1 对于双曲元素 $f, g, f \neq g$, 如果 $A_{1} A_{8}$ 相交于点 $w \in H^{3}$, 则 $f g f$ 也是 双曲的, 且 $A_{f g f}$ 过点 $w, n>2$.

定理 3 对于非单位元素 $f \in M\left(\bar{R}^{*}\right)$, 存在短程线 $L_{1}, L_{2}$, 使得 $f=\sigma_{1} \sigma_{2}$ 当且仅 当 $f$ 共轭于如下形式的元素

$$
h=\left(\begin{array}{ll}
-r^{-1} q & r^{-1} q^{2}-r \\
r^{-1} & -r^{-1} q
\end{array}\right),
$$

其中 $r, q$ 分别是 $h$ 的等距球的半径及球心, $\sigma_{i}(i-1,2)$ 是关于 $L_{i}$ 的 $H-R$ (下同).

推论 2 运动元素不能分解成两个 $H$ $R$ 的复合.

定理 $4 f$ 是严格抛物的当且仅当存 在短程线 $L_{1}, L_{2}$, 使得 $f=\sigma_{1} \sigma_{2}$, 且 $L_{1}, L_{2}$ 有一个公共端点.

定理 5 如果 $f=\sigma_{1} \sigma_{2}$, 则

i) $L_{1}$ 与 $L_{2}$ 在 $H^{n+1}$ 中有交点当且仅 当 $f$ 是椭圆的.

ii) $L_{1}$ 与 $L_{2}$ 在 $\bar{H}^{n+1}$ 中无交点当且仅 当 $f$ 是斜驶的.

iii） $L_{1}$ 与 $L_{2}$ 有一个公共端点当且仅 当 $f$ 是严格抛物的.

\section{参考文 献}

[1] Maskit, B., Grundlehren der Mashematischen Wissenschaft, Springer-Verlag, Berlin, 1988.

[2]方爱农,科学通报,1991,36(3): 237-238.

王仙桃方爱农 (湖南大学应用数学系, 长沙 410082)

- 国家自然科学基金和天元基金资助课题。 